\title{
Airport arrivals screening during pandemic (H1N1) 2009 influenza in New South Wales, Australia
}

\section{Praveena J Gunaratnam $\mathrm{BA}, \mathrm{MPH}$ Public Health Officer Trainee Centre for Epidemiology and Evidence, and DrPH \\ Candidate $^{2}$ \\ Sean Tobin BMBS, MPH, FAFPHM Medical Epidemiologist Health Protection NSW \\ Holly Seale BSc, MPH, PhD Senior Research Fellow 2 \\ Antew Marcich \\ MBBS, MPH, DCH General Practice Registrar ${ }^{3}$ \\ Jeremy McAnulty \\ MBBS, MPH, FAFPHM Director \\ Health Protection NSW \\ INSW Health, Sydney, NSW. \\ 2 School of Public Health and Community Medicine \\ University of New South \\ Wales, Sydney, NSW. \\ 3 Mount Martha Village Clinic, Melbourne, VIC \\ pguna@ \\ doh.health.nsw.gov.au}

MJA 2014; 200: 290-292 doi: 10.5694/mjal3.10832
D uring the DELAY and CONTAIN phases of pandemic (H1N1) 2009 influenza, New South Wales Health conducted, at the request of the Australian Government, screening of passengers at Sydney Airport. The aim was to delay entry and minimise spread of the pandemic in Australia.1,2 In this study, we examined the effectiveness of this intervention, in order to inform its future use at the state and national level.

On 27 April 2009, two clinics were established at Sydney Airport, staffed by nurses from the local area health service, with public health support from the NSW Ministry of Health. On-board announcements were made before landing, and all incoming international passengers were asked to declare any symptoms or possible contact with a person with influenza A(H1N1)pdm09 by completing a health declaration card. Additionally, thermal imaging scanners with a set point of $38^{\circ} \mathrm{C} \pm 2^{\circ} \mathrm{C}$ were used to detect febrile passengers. 3,4

Public health staff triaged and assessed passengers who self-reported symptoms or were detected by thermal scanners according to the case definition current at the time (Box 1). Passengers who met the case definition answered a questionnaire, underwent a brief clinical assessment and had nose and throat swabs taken, which were sent to a pathology laboratory for testing. All demographic, exposure and health assessment data collected at the airport clinics were entered in real time into NetEpi, a national webbased public health data collection sys-

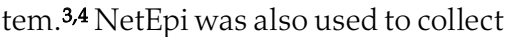
data for all patients and contacts presenting anywhere with an influenzalike illness, and to assign case status when known. ${ }^{3}$

As airport clinics were being operationalised, media warnings were issued to the general public asking people with symptoms to call their local doctor and, if required, to go to an emergency department for assessment. $^{3}$

Abstract

Objective: To examine the effectiveness of airport screening in New South Wales during pandemic (HIN1) 2009 influenza.

Design, setting and participants: Analysis of data collected at clinics held at Sydney Airport, and of all notified cases of influenza A(H1N1)pdm09, between 28 April 2009 and 18 June 2009.

Main outcome measures: Case detection rate per 100000 passengers screened, sensitivity, positive predictive value and specificity of airport screening. The proportion of all cases in the period detected at airport clinics was compared with the proportion detected in emergency departments and general practice.

Results: Of an estimated 625147 passenger arrivals at Sydney Airport during the period, 5845 (0.93\%) were identified as being symptomatic or febrile, and three of 5845 were subsequently confirmed to have influenza $A(\mathrm{HIN1})$ pdm09, resulting in a detection rate of 0.05 per 10000 screened ( $95 \% \mathrm{Cl}, 0.02-1.14$ per 10 000). Forty-five patients with overseas-acquired influenza A(H1N1)pdm09 in NSW would have probably passed through the airport during this time, giving airport screening a sensitivity of $6.67 \%(95 \% \mathrm{Cl}, 1.40 \%-18.27 \%)$. Positive predictive value was $0.05 \%$ ( $95 \% \mathrm{Cl}, 0.02 \%-0.15 \%)$ and specificity $99.10 \%(95 \% \mathrm{Cl}, 99.00 \%-$ $100.00 \%$ ). Of the 557 confirmed cases across NSW during the period, 290 $(52.1 \%)$ were detected at emergency departments and 135 (24.2\%) at general practices, compared with three $(0.5 \%)$ detected at the airport.

Conclusions: Airport screening was ineffective in detecting cases of influenza $\mathrm{A}(\mathrm{H} 1 \mathrm{N1})$ pdm09 in NSW. Its future use should be carefully considered against potentially more effective interventions, such as contact tracing in the community.

\section{Methods}

Data from airport clinics and on all cases of influenza A(H1N1)pdm09 collected between 28 April 2009 and 18 June 2009 and stored in NetEpi had previously been imported into Microsoft Excel. The number screened was estimated on a pro rata basis as the total number of international passengers arriving at Sydney Airport between 28 April 2009 and 18 June 2009, using monthly data from the Bureau of Infrastructure, Transport and Regional Economics. ${ }^{5}$

The case detection rate of airport screening was calculated as the number of confirmed cases of influenza $\mathrm{A}(\mathrm{H} 1 \mathrm{~N} 1)$ pdm09 detected at the airport per 10000 passengers screened. Sensitivity was calculated as the number of confirmed cases detected at the airport as a proportion of the total number of overseas-acquired cases in the period. Positive predictive value was calculated as the proportion of symptomatic or febrile passengers who tested positive for A(H1N1)pdm09, and specificity as a proportion of the total number of passengers minus the number of those with known overseas-acquired influenza $\mathrm{A}(\mathrm{H} 1 \mathrm{~N} 1)$ pdm09 who were identified as not being symptomatic or febrile. Negative predictive value could not reliably be calculated; as it is possible some passengers not identified as symptomatic or febrile at screening later developed influenza, but did not seek clinical care or testing and so never became confirmed cases. The number of cases detected at the airport was calculated as a proportion of all cases identified between 28 April and 18 June 2009, and compared with the proportion of cases over the same period who were detected at emergency departments and in general practice.

Analysis was performed using Excel (Microsoft) and Stata version 10 (StataCorp).

Ethics approval was not sought as the study used data collected under the Public Health Act 1991 (NSW).

\section{Results}

Results of the analysis are presented in Box 2. There were an estimated 625147 passenger arrivals at Sydney 


\section{Definitions for suspected cases of influenza $A(H 1 N 1) p d m 09, D E L A Y$ and CONTAIN phases ${ }^{3}$ \\ Phase \\ DELAY (24 April 2009 \\ to 21 May 2009) \\ CONTAIN (22 May 2009 \\ to 16 June 2009) \\ Case definition \\ A person with acute febrile respiratory illness, with onset within 7 days of close contact with a person who is a confirmed or an influenza A-positive suspect case of pandemic (HIN1) 2009 influenza virus infection; or onset since 15 April 2009 and within 7 days of travel to Mexico, the United States or Canada. \\ As above but expanded to include contacts of a confirmed case with more minor symptoms. Japan and Panama were added to the list of affected regions on 23 May, and Chile, Argentina and greater metropolitan Melbourne were added on 15 June.}

Airport during the period, of whom 5845 or $0.93 \%$ were identified as being symptomatic or febrile. Of these 5845 , three subsequently were confirmed as having influenza $\mathrm{A}(\mathrm{H} 1 \mathrm{~N} 1)$ pdm09, resulting in a detection rate of 0.05 per 10000 (95\% CI, 0.02-1.14 per 10000). There were 45 people with overseasacquired influenza A(H1N1)pdm09 in NSW who would have probably passed through the airport during this time, giving airport screening a sensitivity of $6.67 \%$ (95\% CI, 1.40\%-18.27\%). Positive predictive value was $0.05 \%$ (95\% CI, 0.02\%-0.15\%), and specificity was $99.10 \%$ (95\% CI, 99.00\%-100.00\%).

Of the 1296 passengers identified as requiring further assessment, the large majority (1144 passengers or $88.27 \%$ ) were detected through health declaration cards. Only 11 of these 1296 passengers $(0.85 \%)$ were detected by the thermal scanners. For the remaining passengers (35 passengers or $2.70 \%$ ), the identification method was either unknown or through other mechanisms, such as referral to the airport clinic by the Australian Quarantine and Inspection Service officers.

Across NSW, there was a total of 557 patients with confirmed cases who had samples collected and sent for laboratory testing between 28 April and 18 June 2009. Samples were obtained from patients seen at the airport clinic, emergency departments, general practices and other settings. Of these, 290 (52.1\%) were detected at emergency departments and 135 (24.2\%) at general practices, compared with three $(0.5 \%)$ at the airport.

\section{Discussion}

Our analysis shows that airport screening in NSW during pandemic (H1N1) 2009 influenza had low sensitivity, detecting far fewer cases during the DELAY and CONTAIN phases compared with emergency departments or general practitioners. The case detection rate of 0.05 per 10000 passengers screened reflects figures in reviews of airport screening in other Australian jurisdictions and other countries. ${ }^{6-10}$ The small number of passengers detected by thermal scanners is also consistent with published estimates of the sensitivity of non-contact infrared thermal image scanners, and the high proportion of influenza infections that are likely to be asymptomatic. ${ }^{11,12}$

Limitations of the study include possible underestimation of the

\section{Screening for influenza A(H1N1pdm09) at Sydney Airport, 28 April 2009 to 18} June 2009

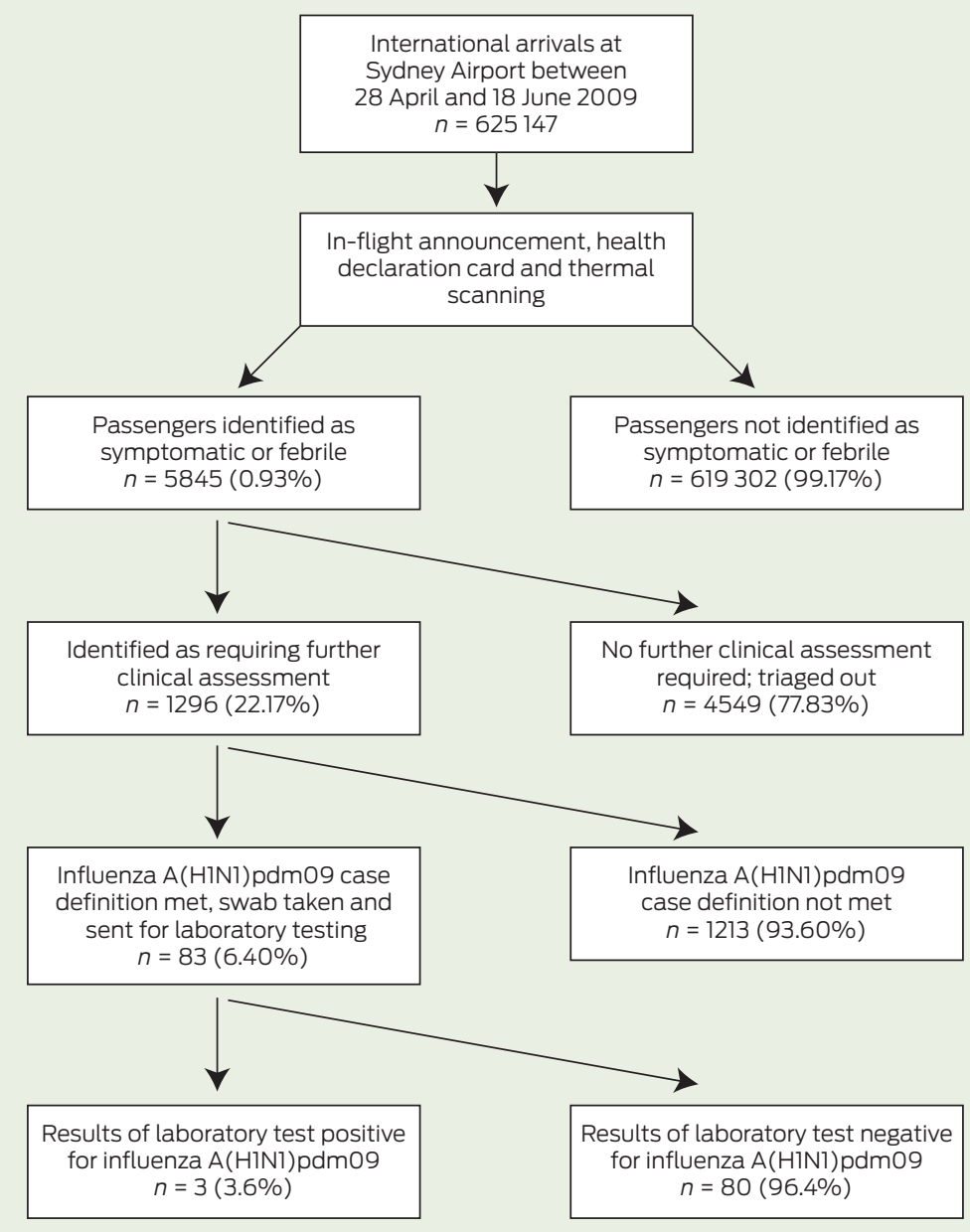


as thermal scanners to be useful in detecting ill passengers. ${ }^{2}$

The cost of staffing airport clinics in NSW has been estimated at about $\$ 50000$ per case detected (NSW Ministry of Health, unpublished data, 2012). Measures such as in-flight announcements and providing health information at airports may be still be useful mechanisms for raising awareness among incoming passengers during future pandemics. However, given the costs associated with staffing airport clinics, careful consideration should be given to deploying resources to airports for largely ineffective screening measures, compared with other activities such as contact tracing in the community.

Acknowledgements: Thanks to Nicola Nel (South East Sydney Local Health District), Paula Spokes and Robin Gilmour (Health Protection NSW) for assistance with data extraction, and Jennie Musto and Robin Gilmour (Health Protection NSW) for review of the paper. Praveena Gunaratnam is employed as a trainee on the NSW Public Health Officer Training Program, funded by the NSW Ministry of Health. She undertook this work while she was based at the Communicable Diseases
Branch, NSW Ministry of Health. The Program is offered in partnership with the University of NSW.

Competing interests: No relevant disclosures.

Received 20 June 2013, accepted 31 Oct 2013.

1 NSW Health Emergency Management Committee. Key recommendations on pandemic (HINI) 2009 influenza. North Sydney: NSW Department of Health, 2010. http://www0. health.nsw.gov.au/pubs/2010/hlnl_2009_key_ recomm.html (accessed Nov 2013).

2 Australian Government Department of Health and Ageing. Review of Australia's health sector response to the pandemic (HINI) 2009: lessons identified. Canberra: Commonwealth of Australia, 2011 http://www.flupandemic.gov. au/internet/panflu/publishing.nsf/Content/ review-2011/\$File/lessons\%2Oidentified-oct11. pdf (accessed Dec 2011).

3 Churches T, Conaty SJ, Gilmour RE, Muscatello DJ. Reflections on public health surveillance of pandemic (HINI) 2009 influenza in NSW. NS W Public Health Bull 2010; 21: 19-25.

4 Spokes PJ, Cretikos MA, Ward JG. Pandemic (HINI) 2009 influenza in NSW: an overview of the public health response. NS W Public Health Bull 2010; 21: 4-9.

5 Australian Government Department of Infrastructure, Transport, Regional Development and Local Government. Aviation: international airline activity 2009. Statistical report. Canberra: Commonwealth of Australia, 2009. http://www.bitre.gov.au/publications/
ongoing/files/International_airline_activity_ CY09.pdf (accessed Mar 2012).

6 Public health measures taken at internationa borders during early stages of pandemic influenza A (HIN1) 2009: preliminary results. Wkly Epidemiol Rec 2010; 85: 186-195.

7 Hale MJ, Horton RS, Baker MG. Screening for influenza A(HINI)pdm09, Auckland International Airport, New Zealand. Emerg Infect Dis 2012; 18: 866-868.

8 Nishiura H, Kamiya K. Fever screening during the influenza (HINl-2009) pandemic at Narita International Airport, Japan. BMC Infect Dis 2011; 11: 111 .

9 Appuhamy RD, Beard FH, Phung HN, et al. The changing phases of pandemic (HINI) 2009 in Queensland: an overview of public health actions and epidemiology. Med J Aust 2010; 192: 94-97.

10 Kelly HA, Priest PC, Mercer GN, Dowse GK. We should not be complacent about our population-based public health response to the first influenza pandemic of the 21st century. BMC Public Health 2011; 11: 78.

11 Bitar D, Goubar A, Descenclos JC. International travels and fever screening during epidemics: a literature review on the effectiveness and potential use of non-contact infrared thermometers. Euro Surveill 2009; 14: pii: 19115.

12 Priest PC, Duncan AR, Jennings LC, Baker MG. Thermal image scanning for influenza border screening: results of an airport screening study. PLOS One 2011; 6: el4490.
2014 Australian

Pain Society 34th

Annual Scientific Meeting

13-16 April 2014

Hotel Grand Chancellor, Hobart

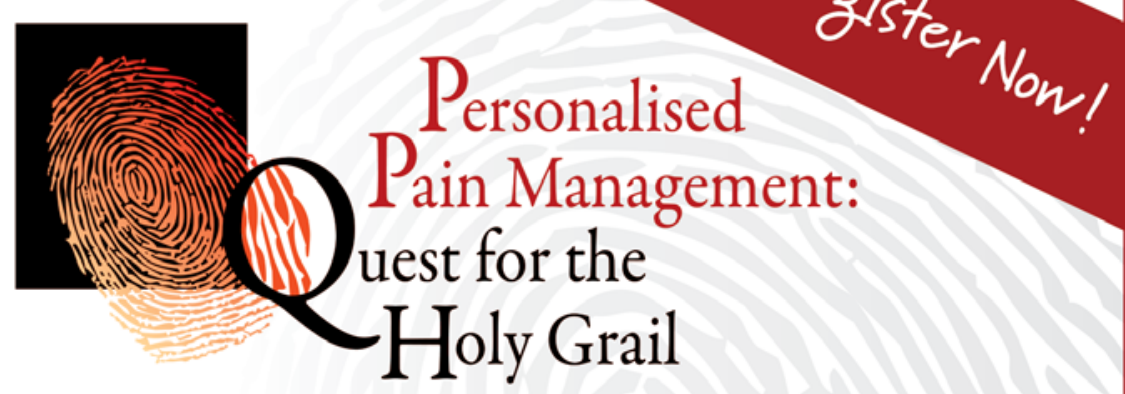

$\nabla$ International Keynote Speakers

\section{Register online: www.dcconferences.com.au/aps2014}

The Australian Pain Society Annual Scientific Meeting is Australia's only multidisciplinary conference offering insights into the complex nature of pain management from a variety of medical, nursing and allied health perspectives.

Stay in beautiful Tasmania for Easter and lose yourself in the wilderness, play golf, go hiking, see works of art and enjoy the rich culture of great food and wine.

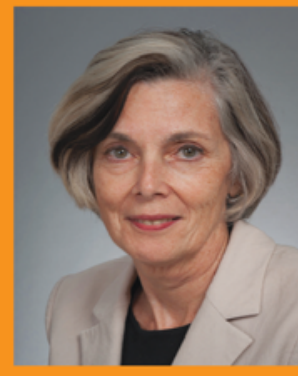

Dr Jane Ballantyne Professor of Anaesthesiology and Pain Medicine, University of Washington, Seattle, USA

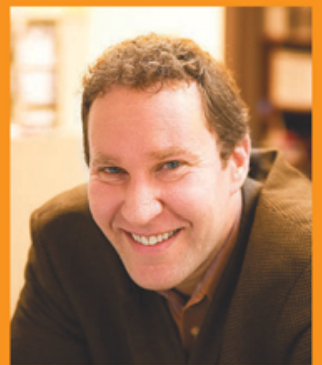

Professor Jeffrey Mogil EP Taylor Professor of Pain Studies and Canada Research Chair, Genetics of Pain McGill University, Montreal, Canada

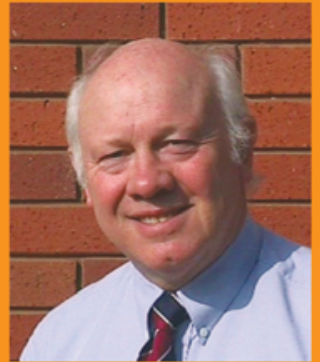

Dr Andrew Moore Director of Pain Research, Nuffield Department of Anaesthetics, University of Oxford, UK 